Kansas State University Libraries

New Prairie Press

\title{
Evaluating Adaptions of Soft Red Winter Wheat in Eastern Region of USA
}

Dilmini Alahakoon

South Dakota State University, dilmini.alahakoon@sdstate.edu

Anne Fennell

South Dakota State University, anne.fennell@sdstate.edu

Jixiang Wu

South Dakota State University, jixiang.wu@sdstate.edu

Follow this and additional works at: https://newprairiepress.org/agstatconference

Part of the Agriculture Commons, and the Applied Statistics Commons

\section{(c) (1) $\Theta($}

This work is licensed under a Creative Commons Attribution-Noncommercial-No Derivative Works 4.0 License.

\section{Recommended Citation}

Alahakoon, Dilmini; Fennell, Anne; and Wu, Jixiang (2017). "Evaluating Adaptions of Soft Red Winter Wheat in Eastern Region of USA," Conference on Applied Statistics in Agriculture. https://doi.org/10.4148/ 2475-7772.1542

This Event is brought to you for free and open access by the Conferences at New Prairie Press. It has been accepted for inclusion in Conference on Applied Statistics in Agriculture by an authorized administrator of New Prairie Press. For more information, please contact cads@k-state.edu. 


\title{
EVALUATING ADAPTIONS OF SOFT RED WINTER WHEAT IN EASTERN REGION OF USA
}

\author{
Dilmini Alahakoon, Anne Fennell, and Jixiang Wu \\ Department of Agronomy, Horticulture, and Plant Science \\ South Dakota State University, Brookings, SD 57007.
}

\begin{abstract}
Identification of winter wheat genotypes that are highly adapted to a wide range of environmental conditions is one of the most important wheat research objectives. Multienvironment trials (METs) under diverse environments is a commonly used practice to evaluate mean performance and yield stability. However, locations used and genotypes planted may vary from year to year which may cause yield stability analysis to be statistically challenging. In this study, we evaluated yield trial data containing 117 eastern soft red winter wheat genotypes that were grown in 35 locations in eastern production areas and four growing seasons (2012/2013 to 2015/2016). We used linear mixed model (LMM) and additive main effect and multiplicative interaction (AMMI) approaches to evaluate the mean performance and yield stability for each season. Genotype and location effects were highly significant at $\alpha=0.001$ for all four seasons and location effects had higher variation compared to genotypic effects. For example, the proportional variance components for location and genotype effects varied from 58-78\% and 4-11\% among seasons. The first two PC score contribution ranged from 40.7 to $67.3 \%$ to the total genotypeenvironment variation for all seasons. Both LMM and AMMI approaches detected that Branson, and MO080108-4 were better performers, thus these two methods were consistent.
\end{abstract}

Key words: stability analysis, eastern soft red winter wheat, linear mixed model, and additive main effect and multiplicative interaction

\section{Introduction}

Wheat is the principal food grain produced in the United States. Winter wheat production represents 70-80\% of total USA production (ERS, 2017). Among wheat crops, soft red winter wheat, accounting for $15-20 \%$ of total production in USA, is grown primarily in states along the Mississippi River and in the eastern states. Flour from eastern soft red winter wheat (ESRWW) is mainly used for cakes, cookies, and crackers in the USA. To ensure consistent and nutritious food supply to the nation, continuous breeding programs aimed at developing varieties with improved grain yield, disease resistance, and end use quality are essential in these areas. Identification of high-yielding winter wheat cultivars that are widely adapted to diverse environmental conditions is highly desired.

Multi-environments trials (METs) under diverse environments are a commonly used practice to evaluate wheat yield stability. For example, uniform eastern and southern red soft winter wheat nursery trials are conducted annually by United States Department of Agriculture. Under this program, more than 30 ESRWW lines are evaluated annually for yield performance as well as many traits to predict their performance. Preferred genotypes for future use are expected to have high-yielding and stable performance in diverse locations and/or years (Gauch et al., 2008). 
To identify the best genotype for a given location, genotype location interaction (GEI) can be used as a factor since it is the main component that affecting to the stability of a variety.

Because of the complex behaviour of GEI, a number of statistical methods have been proposed in order to quantify genotypic stability. Several commonly used statistical methods for yield stability analysis include Finlay and Wilkinson's (FW) regression coefficients (Finlay and Wilkinson, 1963), linear mixed model (LMM) approaches, genotype main effect and genotype environment interaction (GGE) biplot (Yan and Kang, 2003), and additive main effects and multiplicative interaction (AMMI) method (Gauch,1992).

The FW regression method allows us to compare the performance of set of varieties grown in different environments by linear regression coefficient and coefficient of determination. Because environment index (EI), which is used for yield stability evaluation is defined as the mean yield of all varieties for each environment and years. Yield stability is highly dependent on the varieties used in the trial. The AMMI method evaluates stability of crops by integrating both analysis of variance (ANOVA) and principal component analysis (PCA) to analyse METs. In this model, ANOVA is used to analyse genotype and environment main effects while PCA is for interactions between genotypes and environments (Silveria et al., 2012). GGE biplot analysis, which is based on PCA, is another effective method to explore the yield trials in different locations. It also allows visual examination of the relationships among the test environments, genotypes and the genotype environment interactions. Alternatively, statisticians have also applied ANOVA and LMM approaches to evaluate yield stability (Smith, 2005). The LMM approaches provide more flexibility to deal with complex models and missing and/or unbalanced data (Nuvunga et al., 2015).

The objective of this study was to evaluate yield stability for each ESRWW genotype in the recent four seasons of yield trials by using LMM approach and AMMI method and to determine those wheat genotypes that had both high-yielding potential and wide adaption in eastern area of USA. The yield trial data used in this study included 117 ESRWW, four growing seasons (2012/2013 to 2015/2016), and 35 locations across the eastern region of USA. The results will help to identify desirable winter wheat genotypes that are suitable in eastern region of USA.

\section{Materials and Methods}

\subsection{Materials}

The data set with 117 ESRWW genotypes that were grown in 35 locations, across 19 states in eastern region of USA, for four seasons (2012/13-2015/16) was used for this study. The data used in this study were individual genotypic means for each environment and were from Uniform Eastern Soft Red Winter Wheat Nursery Report published by United States Department of Agriculture.

\subsection{Statistical analysis}

First, we obtained genotypic and location means for grain yield and heading date across locations, genotypes, and seasons. Due to the large number of genotypes, we present mean trait values for only the top 25 genotypes in Table 2.

Due to highly unbalanced data structure across four growing seasons, we conducted separate LMM and AMMI analyses for each growing season. In addition, since only individual 
genotypic means for each location were available, genotype-location interactions could not be separated from the model for each growing season. The linear model is as follows:

$Y_{i j}=\mu+G_{i}+E_{j}+\varepsilon_{i j}$

where $Y_{i j}$ is the mean yield of genotype $i$ in location $j, \mu$ is the population mean, $G_{i}$ and $E_{j}$ are the genotype and location effects and $\varepsilon_{i j}$ is a residual including GEI that confounded with random error. In this study, we treated both genotype and location effects random.

Using LMM approaches, we calculated variance component, proportional variance component, estimated fixed effect, and predicted random effects for genotypes and locations. The standard error for each parameter was calculated with 10-fold jackknife resampling technique (Wu et al., 2012).

Though genotype-environment interaction in the model (1) could not be separated from the residual $\varepsilon_{i j}$, with the following AMMI model, it is possible to partially separate GEI effects (Zobel et al., 1988).

$\mathrm{Y}_{\mathrm{ij}}=\mu+\mathrm{G}_{\mathrm{i}}+\mathrm{E}_{\mathrm{j}}+\sum_{\mathrm{k}=1}^{\mathrm{M}} \lambda_{\mathrm{k}} \alpha_{\mathrm{ik}} \gamma_{\mathrm{jk}}+\rho_{\mathrm{ij}}$

$Y_{i j}, \mu, G_{i}$ and $E_{j}$ were defined in equation $1 ; \lambda_{k}$ is a singular value of the $k$ axis in the PCA; $\alpha_{\mathrm{ik}}$ and $\gamma_{\mathrm{jk}}$ are PC scores related to genotype and environmental factors, respectively; $\mathrm{M}$ is the number of principal components retained in the model; $\rho_{\mathrm{ij}}$ is the residual (Silveria et al, 2012).

We used R (version 3.3.2) statistical software under the RStudio (RStudio, 2016) environment to conduct LMM analysis (model 1) with the minque package (Wu, 2014) and AMMI analysis (model 2) with the agricolae package (Mendiburu, 2016).

\section{Results and Discussion}

\subsection{Mean grain yield and heading date}

According to Table 1, 39, 39, 31, and 30 genotypes and 21, 21, 24, and 24 locations were used in each season for the study. Genotypic mean across location for each season ranged from 72.47 to $79.51 \mathrm{bu} / \mathrm{ac}$.

The top 25 genotypes recoded for highest mean yield and their heading date across all environments and years are shown in Table 2. The mean grain yield ranged from 96.44 to 81.2 bu/ac and their heading date ranged from 123.1 to 138.1 Julian days (Table 2). Hilliard, a check cultivar reported as the highest yielding genotype among all tested genotypes and Branson and MO080104, the other two check cultivars, showed comparatively higher mean yield of 81.85 and $82.47 \mathrm{bu} / \mathrm{ac}$ (Table 2). Hilliard was also reported as a high yielding variety in many states for state yield trials including Tennessee (West et al, 2016) and Wisconsin (Conley, 2016). As stated by Friesen et al (2015), forty-one (41) genotypes show mean grain yield greater than the population mean of $78.07 \mathrm{bu} / \mathrm{ac}$ (data not shown).

The top two locations with greater mean yield were Ithaca, NY (93.37 bu/ac) and Arlington, (WI) (92.63 bu/ac) (Table 3). Mead was reported with the lowest mean yield of 45.89 bu/ac among all locations. The season mean yield of genotypes across locations ranged from 72.47 to $79.51 \mathrm{bu} / \mathrm{ac}$ (Table 1), showing comparatively constant values across seasons. Since the breeders 
selected the high yielding genotypes from new lines reported from these trials in each year, these results agreed with the study reported by Friesen et al (2015).

\subsection{Variance components and genotypic effects}

Significant location variance $(58-78 \%)$ for four years was detected (Table 4$)$, indicating that environmental conditions across different locations played a major role on grain yield. Campbell et al. (1976) reported the similar results in their study for Uniform ESRWW Nursery data. Genotypic effect contributed $4-11 \%$ of the total variance for different seasons. The results agreed with other published results (Dia et al, 2016 and Mohammadi et al, 2015). In 2015, Friesen et al also reported less than $10 \%$ genotypic variance for spring wheat (Friesen et al, 2015).

The checks Branson, MO080104, and Hilliard showed highest predicted effects for 2012/13, 2013/14, and 2015/16 seasons. The genotypic effects for Branson (2012/13), MO080104 (2013/14), and Hilliard (2015/16) were 5.7, 7.5 and 16 bu/ac, respectively (Table 5). Hilliard, Branson, and MO080104 found among genotypes with mean yield higher than $81.2 \mathrm{bu} / \mathrm{ac}$ in Table 2. The lowest effect for yield was -14.5 (reported in OH10-219-65 for 2015/16). The highest location effects for all seasons were 24 (Warsaw in 2012/13), 39 (Battle Ground in 2013/14), 30 (Urbana in 2014/15), and 29 (Arlington in 2015/16). The lowest (bottom 5) location effects were for Missouri, Illinois, Arkansas, Nebraska and Tennessee states more than one time (Table 5). Agreeing with Table 5, Table 3 showed Warsaw, Battle Ground, Urbana, and Arlington as high yielding locations and the reported mean yields are 80.46, 85.62, 90.42, and 92.63 bu/ac. Mead, (NE) (45.89 bu/ac), Marianna, (AK) (50.14 bu/ac), and Columbia, (MO) (53.76bu/ac) reported low mean yields among locations.

\subsection{Stability analysis}

AMMI biplot is constructed by plotting the first principal component (PC1) scores of the genotypes and the environments against their respective scores for the second principal component (PC2). Total contribution from PC1 and PC2 scores ranged from 45.8 to $67.3 \%$ to the total GEI variance among four seasons (Figure 1a-d). Branson, MO080104 and Hilliard showed high yield for all seasons (Figure 2a-d). OH08-180-48, MO080104, MDC07026-F2-19-13-1, and Hilliard showed the highest mean yield for each season. Warsaw, Ithaca, Urbana, and Arlington were identified as high yielding locations in the present study by AMMI analysis. Low yielding locations for the four seasons were Milan, Marianna, Knoxville, and Columbia (Figure 1).

Highly stable genotypes located close to 0 in PC1 axis and for season 2012/13 highly stable genotypes were MD04W249-11-12, VA08MAS-369 (Figure 2a). Genotypes 0762A1-2-8 and $\mathrm{OH} 07-263-3$ were reported for highest stability in season 2013/14 (Figure 2b). Genotype TN 1505 located close to 0\% (PC1) showing the highest stability for season 2014/15 (Figure 2c). Genotype 04620A1-1-7-4-17 showed highest stability for season 2015/16. Genotypes with high mean yield for season 2012/13 are LCS19228, Shirley and KWS008 and for season 2013/14 are LCS229, MO080104. MDC07026-F2-19-13-1 and MO121058 showed high mean performance for season 2014/15. In 2015/16 season, Hilliard, Branson, DH11SRW8-59 and OH09-207-68 report high mean performance. Moreover, these high performance varieties can be seen among top 25 genotypes (Table 2) and genotypes with high predicted effect (Table 5).

Two statistical approaches that we used to evaluate ESRWW genotypes are equally applicable for the present data. As for an example, in season 2012/13,2013/14, and 2014/15, LMM 
approach showed 5.22, 7.49, and 6.44 bu/ac predicted effects for MO080104 keeping among top five (Table 5). AMMI also graphed MO080104 in 2012/13, 2013/14, and 2014/15 seasons among high yielding genotypes (Figure 2a). Both these two methods have shown comparatively consistent results for most genotypes. Since LMM and AMMI derived from same parameters, this observation is acceptable (Piepho, 1998). For evaluation of ESRWW genotypes, we can use one of these two methods in future.

\section{Conclusions}

In this study, we applied both LMM and AMMI methods to analyse soft red winter wheat yield trial data including 117 genotypes, four growing seasons (2012/2013 to 2015/2016), and 35 locations across the eastern region of USA. Results showed that genotype and location effects were significant at $\alpha=0.001$ for all tested seasons. Location effects showed a higher variation than genotypic effects (58-78\% vs 4-11\%). Check varieties performed well, showing the highest effects for three tested seasons. Contribution from the first two PC scores ranged from $40.7 \%$ to $67.3 \%$ to the total GEI variation among seasons. Warsaw, Ithaca, Urbana and Arlington were high yielding locations while Knoxville, Columbia, Marianna and Milan were the lowest yielding locations. Branson, OH08-180-48, Hilliard, and DH11SRW8-59 showed higher yield than the population mean. The results were consistent between both LMM and AMMI approaches in the present study.

\section{References}

Campbell, L.G. and Lafever, H.N. (1976). Cultivar X Environment Interactions in Soft Red Winter Wheat Yield Tests. Crop Science, 17(4):604-608.

Conley, S., Roth, A., Gaska, J., and Smith, D., (2016). Wisconsin winter wheat performance trials 2016. Retrieved June 04, 2017, from http://www.coolbean.info/library/documents/A3868_WisconsinWinterWheatTrials_2016 FINAL.pdf

Dia, M., Wehner, T.C., Hassell, R., Price, D.S., Boyhan, G.E., Olson, S., King, S., Davis, A.R. and Tolla, G.E. (2016). Genotype $\times$ Environment Interaction and Stability Analysis for Watermelon Fruit Yield in the United States. Crop Science, 56:1645-1661.

Economic Research Service, United States Department of Agriculture. (2017). Wheat data. Retrieved May 16, 2017, from https://www.ers.usda.gov/data-products/wheat-data/

Finlay, K. W. and Wilkinson, G. N. (1963). The analysis of adaptation in a plant breeding programme. Australian Journal of Agriculture, 14:742-54. Retrieved August 21, 2017, from http://citeseerx.ist.psu.edu/viewdoc/download?doi=10.1.1.452.8169andrep=rep1 andtype= pdf

Friesen, L.F., Brûlé-Babel, A.L., Crow, G.H. and Rothenburger, P.A. (2015). Mixed model and stability analysis of spring wheat genotype yield evaluation data from Manitoba, Canada. Canadian Journal of Plant Science, 96:305-320.

Gauch, H.G., H.P. Piepho, P. Annicchiaricoc, 2008. Statistical analysis of yield trials by AMMI and GGE. Further considerations. Crop Sci. 48:866-889.Gauch, H.G. (1992). Statistical Analysis of Regional Yield Trials - AMMI analysis of factorial designs, Amsterdam: 
Elsevier. Hildebrand, P.E., 1983. Modified Stability Analysis. Agronomy Journal, 76:271- 274.

Mendiburu, F. (2016). Agricolae: Statistical Procedures for Agricultural Research. R package version 1.2-4. https://CRAN.R-project.org/package=agricolae.

Mohammadi, R., Farshadfar, E. and Amri, A. (2015). Interpreting genotype $\times$ environment interactions for grain yield of rain fed durum wheat in Iran. The Crop Journal, 3(6):526535.

Nuvunga, J.J., Oliveira, L.A., Pamplona, A.K., Silva, C.P., Lima, R.R. and Balestre, M., (2015). Factor analysis using mixed models of multi-environment trials with different levels of unbalancing. PubMed. 14(4):14262-78.

Piepho, H.P. (1998). Methods for comparing the yield stability of cropping systems. Journal of Agronomy and crop science. 180:193-213

Silveira, L.C.I., Kist, V., Paula, T.O.M., Barbosa, M.H.P., Peternelli, L.A. and Daros, E. (2012). AMMI analysis to evaluate the adaptability and phenotypic stability of sugarcane genotypes. Scientia Agricola, 70 (1), 27-32.

Smith, A. B., Cullis, B. R. and Thompson, R. (2005). The analysis of crop cultivar breeding and evaluation trials: An overview of current mixed model approaches. Journal of Agricultural Science, 143 (6), 449-462.

R Core Team (2016). R: A language and environment for statistical computing. R Foundation for Statistical Computing, Vienna, Austria. URL https:/www.R-project.org/.

West, D., Kincer, D., Blair, T., and Montgomery, G. (2016). Wheat variety performances tests in Tennessee. Retrieved May 16, 2017, from http://news.utcrops.com/wpcontent/uploads/2016/08/2016-Wheat-Variety-Report.pdf.

Wu, J. (2014). minque: An R Package for Linear Mixed Model Analyses. R package version 1.1. https://CRAN.R-project.org/package=minque.

Wu, J., Bondalapati, K., Glover, K., Berzonsky, W., Jenkins, J.N. and McCarty, J.C. (2013). Genetic analysis without replications: Model evaluation and application in spring wheat. Euphytica 190:447-458.

Yan, W. and M. S. Kang. 2003. GGE Biplot Analysis: A Graphical Tool for Breeders, Geneticists, and Agronomists. Biometrics 59:735-736.

Zobel, R.W.; Wright, A.J.; Gauch, H.G. 1988. Statistical analysis of a yield trial. Agronomy Journal 80: 388-393. 
Table 1. Number of genotypes, locations and mean yield for each season.

\begin{tabular}{lrrr}
\hline Season & Number of genotypes & Number of locations & Mean yield (bu/ac) \\
\hline $2012 / 13$ & 39 & 21 & 72.48 \\
$2013 / 14$ & 39 & 21 & 78.86 \\
$2014 / 15$ & 31 & 24 & 72.47 \\
$2015 / 16$ & 30 & 24 & 79.51 \\
\hline
\end{tabular}


Table 2. Mean yield of top 25 genotypes across seasons and their heading date.

\begin{tabular}{lrr}
\hline Genotype & $\begin{array}{l}\text { Yield } \\
\text { (bu/ac) }\end{array}$ & $\begin{array}{l}\text { Heading date } \\
\text { (Julian days) }\end{array}$ \\
\hline Hilliard & 96.44 & 125.23 \\
DH11SRW8-59 & 94.12 & 127.98 \\
MD09W272-8-4-14-6 & 88.36 & 124.60 \\
KWS 078 & 87.57 & 127.04 \\
OH09-207-68 & 87.32 & 124.74 \\
VA11W-108 & 86.91 & 136.39 \\
MD09W272-8-4-14-8 & 86.79 & 124.18 \\
VA11W-313 & 86.58 & 121.67 \\
KWS023 & 85.05 & 136.85 \\
VA11W-279 & 84.76 & 123.10 \\
MD09W272-8-4-13-3-15 & 84.66 & 123.54 \\
MO110799 & 84.35 & 138.07 \\
P0762A1-2-8 & 84.07 & 136.69 \\
KWS024 & 83.84 & 137.74 \\
LCS321 & 83.69 & 136.54 \\
04620A1-1-7-4-17 & 83.39 & 127.45 \\
LCS229 & 82.75 & 135.22 \\
IL09-3264 & 82.59 & 134.62 \\
P0722A1-1-7-4-17 & 82.49 & 136.73 \\
MO080104 & 82.47 & 131.06 \\
Branson & 81.85 & 130.83 \\
VA11W-230 & 81.66 & 135.75 \\
MDC07026-F2-19-13-1 & 81.28 & 131.83 \\
AR06050-7-2 & 81.26 & 125.09 \\
IL07-18533-3 & 81.20 & 134.59 \\
\hline
\end{tabular}


Table 3. Mean yield and heading date for each location across seasons.

\begin{tabular}{lrr}
\hline Location & Yield (bu/ac) & Heading date (Julian days) \\
\hline Ithaca & 93.37 & 150.56 \\
Arlington & 92.63 & $\mathrm{NA}$ \\
Logan Co & 91.03 & 124.23 \\
Urbana & 90.42 & 136.92 \\
West Lafayette & 89.32 & 138.28 \\
Griffin & 87.93 & 109.29 \\
Battle Ground & 85.62 & 134.21 \\
Raleigh & 85.22 & 111.13 \\
Champaign & 84.31 & 139.16 \\
Blacksburg & 80.71 & 129.26 \\
Warsaw & 80.46 & 122.28 \\
Napoleon & 79.33 & 142.57 \\
Clarksville & 76.08 & 132.39 \\
New Haven & 75.96 & 142.45 \\
Lafayette & 74.57 & 139.75 \\
Lexington & 74.01 & 128.84 \\
Oconto & 73.36 & $\mathrm{NA}$ \\
Knoxville & 72.91 & $\mathrm{NA}$ \\
Ingham Co & 72.52 & $\mathrm{NA}$ \\
Nairn & 71.89 & 118.79 \\
Brownstown & 71.28 & 133.66 \\
Harrisburg & 69.24 & 111.25 \\
Stuttgart & 69.01 & 151.60 \\
Mason & 68.88 & 105.90 \\
Schochoh & 68.78 & 131.52 \\
Winfield & 67.43 & 117.62 \\
Webberville & 64.34 & 148.80 \\
Plymouth & 63.43 & 113.10 \\
Custar & 63.02 & 142.97 \\
Milan & 58.20 & $\mathrm{NA}$ \\
Columbia & 53.76 & $\mathrm{NA}$ \\
Marianna & 50.14 & \\
Mead & 45.89 & $\mathrm{~N}$ \\
Clayton & & $\mathrm{N}$ \\
Windfall & & 159 \\
\hline
\end{tabular}


Table 4. Proportional variance components from LMM for location and genotype.

\begin{tabular}{ccccc} 
& \multicolumn{4}{c}{ Season } \\
\cline { 2 - 5 } & $12 / 13$ & $13 / 14$ & $14 / 15$ & $15 / 16$ \\
\hline Location & $0.58^{*}$ & $0.78^{*}$ & $0.77^{*}$ & $0.66^{*}$ \\
Genotype & $0.04^{*}$ & $0.04^{*}$ & $0.06^{*}$ & $0.11^{*}$ \\
Error & $0.38^{*}$ & $0.18^{*}$ & $0.17^{*}$ & $0.22^{*}$ \\
\hline
\end{tabular}

* Significant at 0.001 
Table 5. The top 5 and bottom 5 (- sign) predicted random effects for genotypes and locations for all seasons.

\begin{tabular}{|c|c|c|c|c|}
\hline Season & Genotype & $\begin{array}{l}\text { Predicted } \\
\text { effect }\end{array}$ & Location & $\begin{array}{l}\text { Predicted } \\
\text { effect }\end{array}$ \\
\hline \multirow[t]{9}{*}{$2012 / 13$} & Branson & 5.69 & Warsaw & 23.92 \\
\hline & OH08-180-48 & 5.44 & Ithaca & 23.02 \\
\hline & Shirley & 5.37 & West Lafayette & 20.51 \\
\hline & MO080104 & 5.22 & Harrisburg & 15.91 \\
\hline & VA10W-21 & 5.10 & Griffin & 15.90 \\
\hline & NC09-20768 & -6.09 & Knoxville & -20.15 \\
\hline & AR00255-16-1 & -5.74 & Columbia & -17.65 \\
\hline & GA04121-11E26 & -5.51 & Brownstown & -17.64 \\
\hline & ARS07-0525 & -5.19 & Winfield & -12.97 \\
\hline \multirow[t]{9}{*}{$2013 / 14$} & MO080104 & 7.49 & Battle Ground & 38.92 \\
\hline & VA11W-108 & 7.26 & Ithaca & 28.75 \\
\hline & KWS023 & 5.58 & Blacksburg & 25.85 \\
\hline & IL07-19334 & 5.33 & Griffin & 22.91 \\
\hline & Branson & 5.23 & Clarksville & 15.60 \\
\hline & OH07-264-35 & -8.14 & Mead & -41.18 \\
\hline & NC08-140 & -7.47 & Harrisburg & -29.04 \\
\hline & NC10-23663 & -7.34 & Champaign & -19.42 \\
\hline & MSU Line F0013R & -6.25 & Columbia & -15.59 \\
\hline \multirow[t]{9}{*}{$2014 / 15$} & MDC07026-F2-19-13-1 & 8.33 & Urbana & 29.93 \\
\hline & MO 121058 & 7.37 & Champaign & 23.40 \\
\hline & MO080104 & 6.44 & Arlington & 19.70 \\
\hline & VA11W-106 & 6.08 & Logan Co. & 18.49 \\
\hline & AR05094-4-1 & 4.53 & Lafayette & 16.89 \\
\hline & MD09W272-8-4-13-3 & -11.99 & Mead & -43.19 \\
\hline & OH07-206-69 & -9.35 & Columbia & -31.90 \\
\hline & IL02-19463-7 & -6.54 & Nairn & -24.92 \\
\hline & KY05C-1369-14-6-3 & -6.45 & Marianna & -20.31 \\
\hline \multirow[t]{9}{*}{$2015 / 16$} & Hilliard & 15.95 & Arlington & 29.05 \\
\hline & DH11SRW8-59 & 13.69 & Urbana & 28.54 \\
\hline & Branson & 9.52 & Nairn & 27.03 \\
\hline & MD09W272-8-4-14-6 & 8.36 & West Lafayette & 26.74 \\
\hline & KWS 078 & 7.60 & Champaign & 24.96 \\
\hline & OH10-219-65 & -14.50 & Marianna & -31.18 \\
\hline & KY06C-1195-37-2-5 & -13.83 & Milan & -21.16 \\
\hline & TN1603 & -12.97 & Warsaw & -18.24 \\
\hline & Pioneer Brand 25R46 & -12.51 & Battle Ground & -17.12 \\
\hline
\end{tabular}




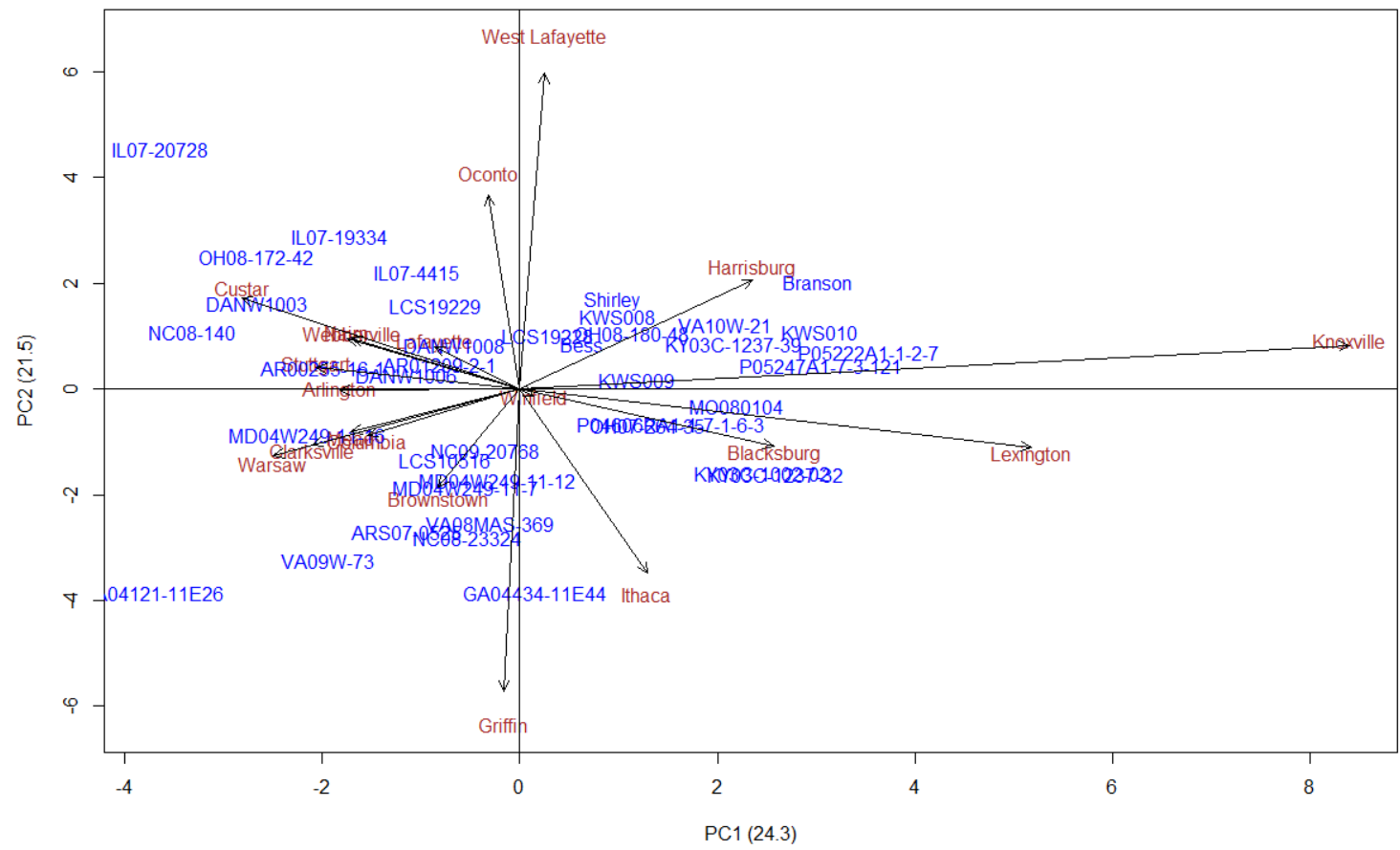

a

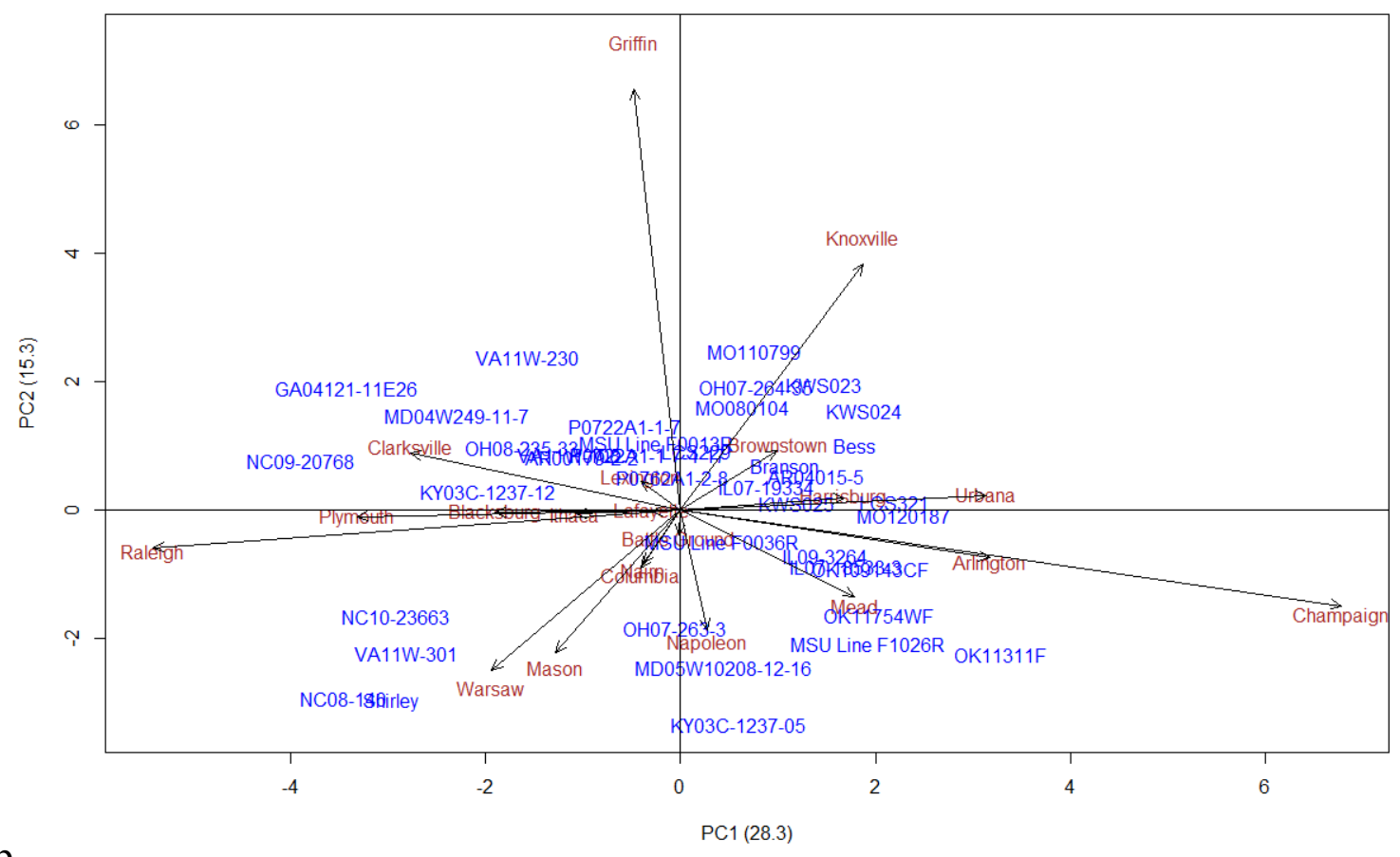

b 


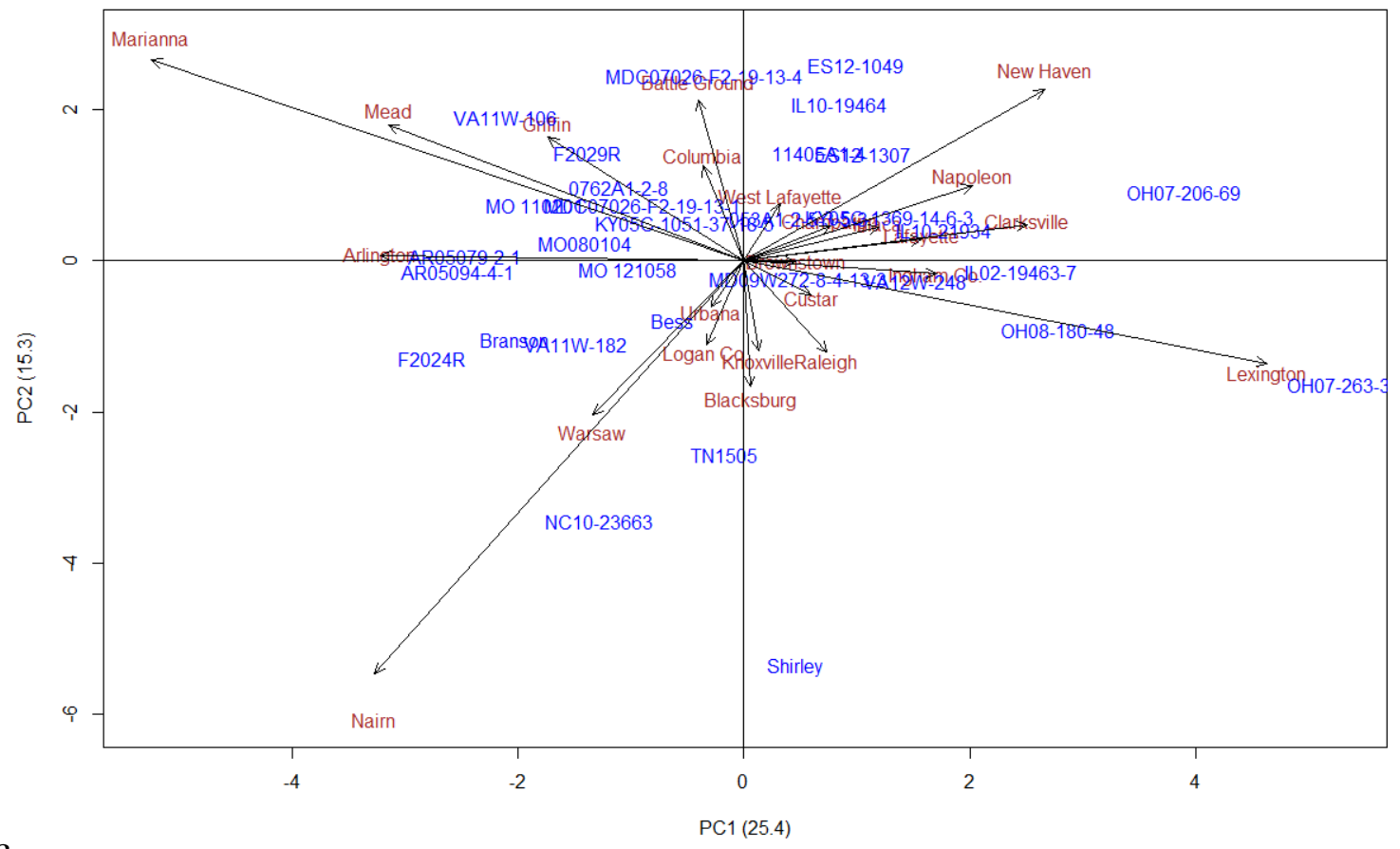

$\mathrm{c}$

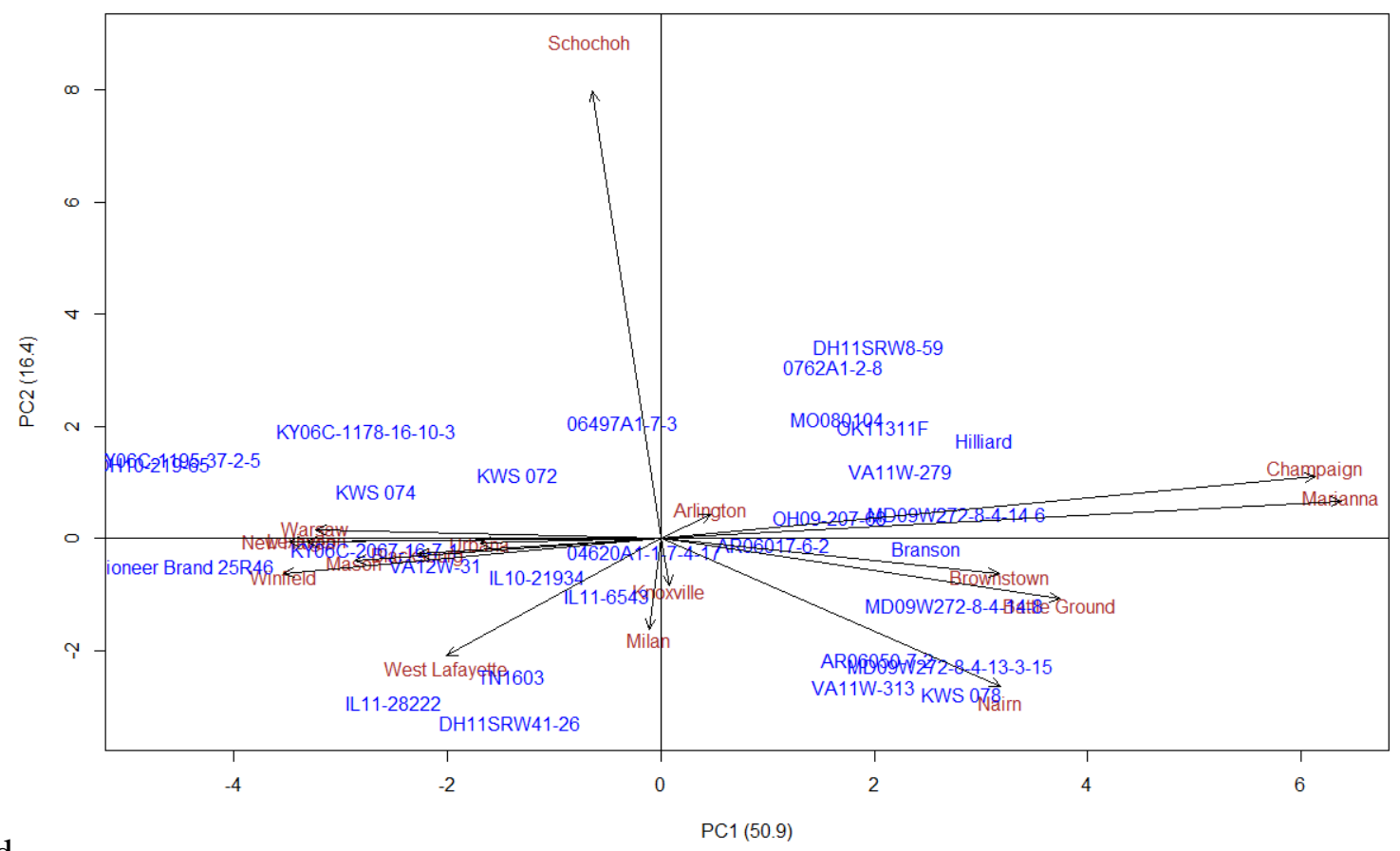

d

Figure 1. Principal component (PC1 and $\mathrm{PC} 2$ ) analysis plots for grain yield (bu/ac) of 39 genotypes and 21 locations for season 2012/13 (a), 2013/14 (b), 31 genotypes and 24 locations for season 2014/15 (c) and 30 genotypes and 24 locations for 2015/16 (d). Blue and red letters indicate genotypes and locations, respectively. 


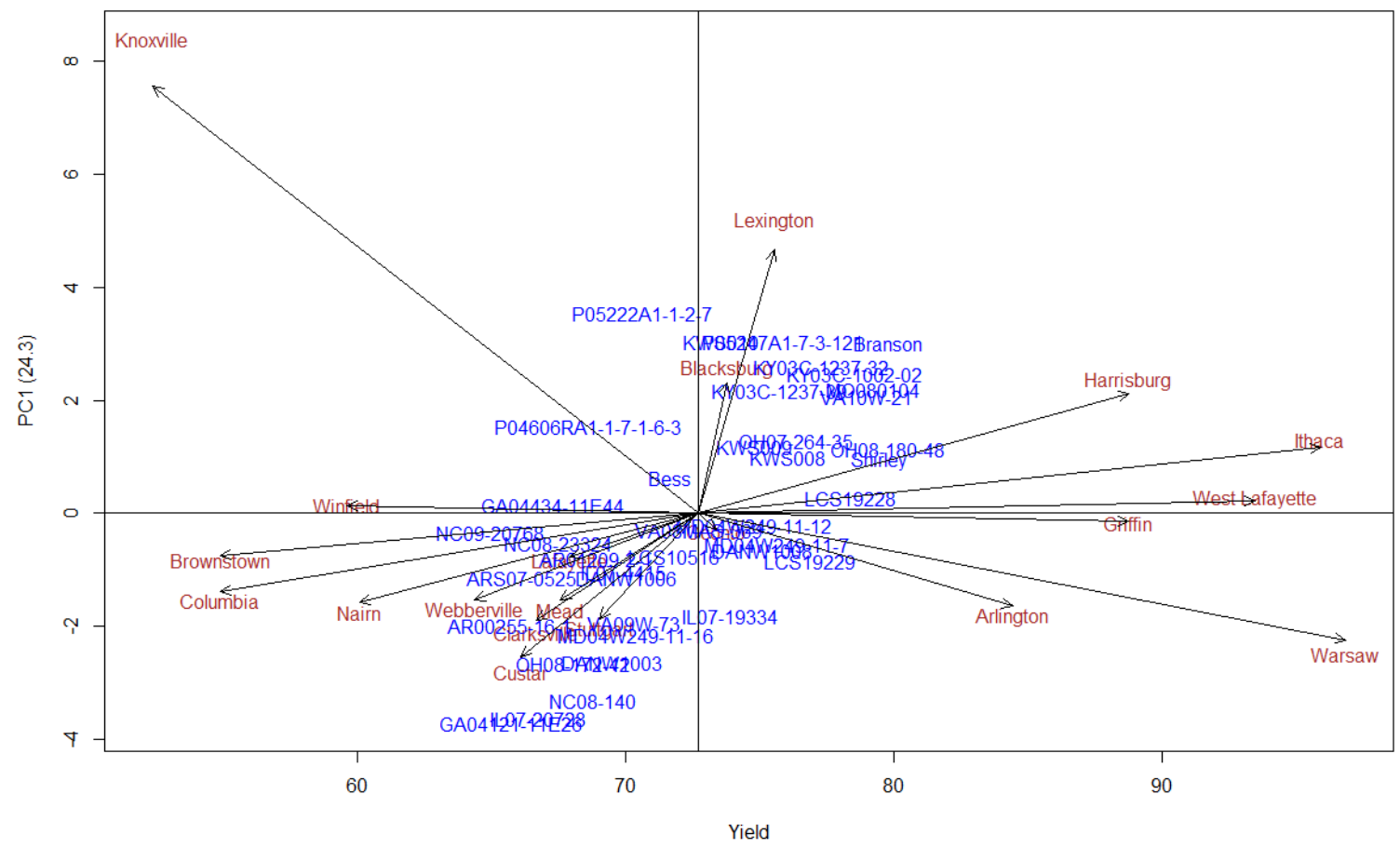

a

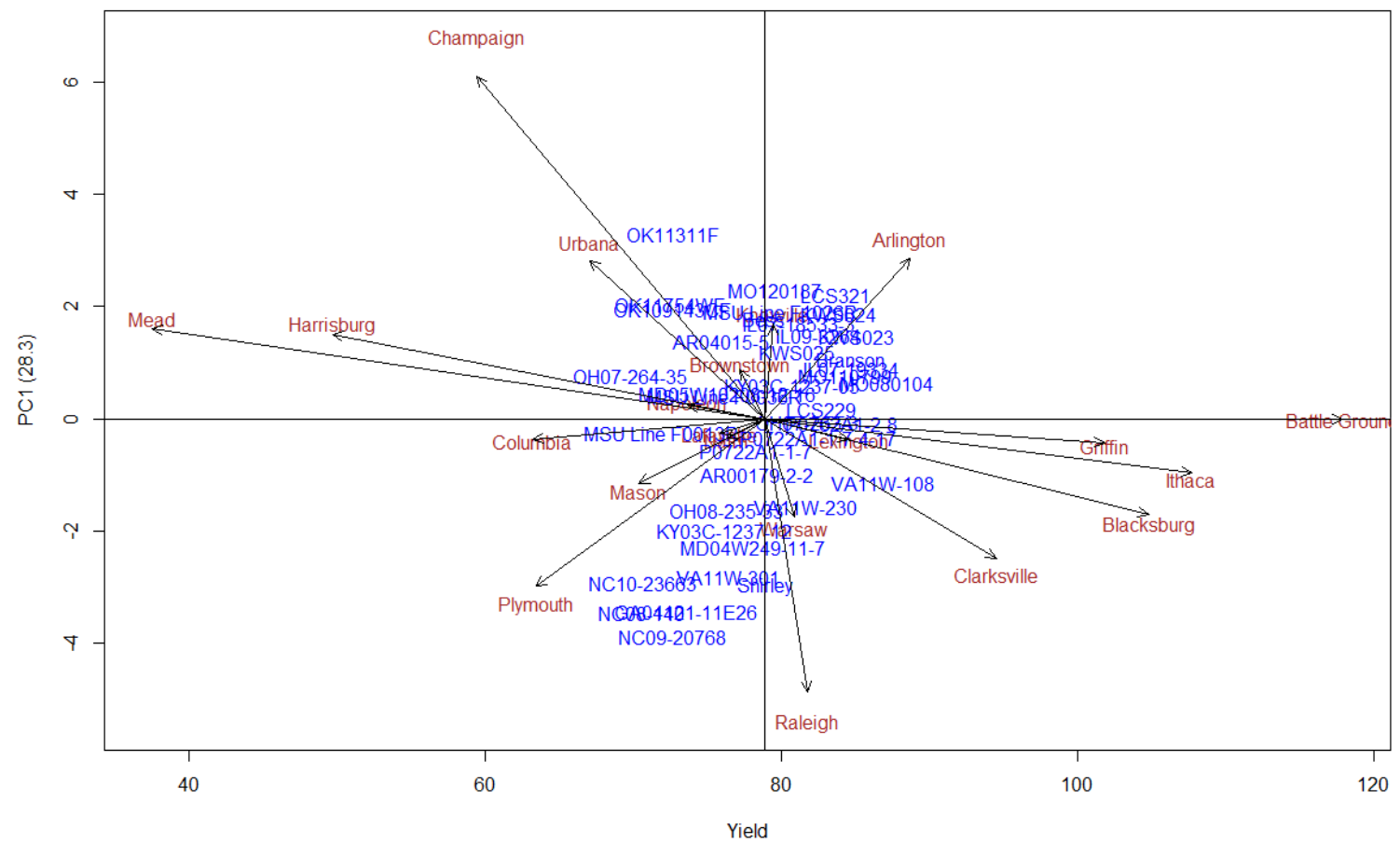

b 


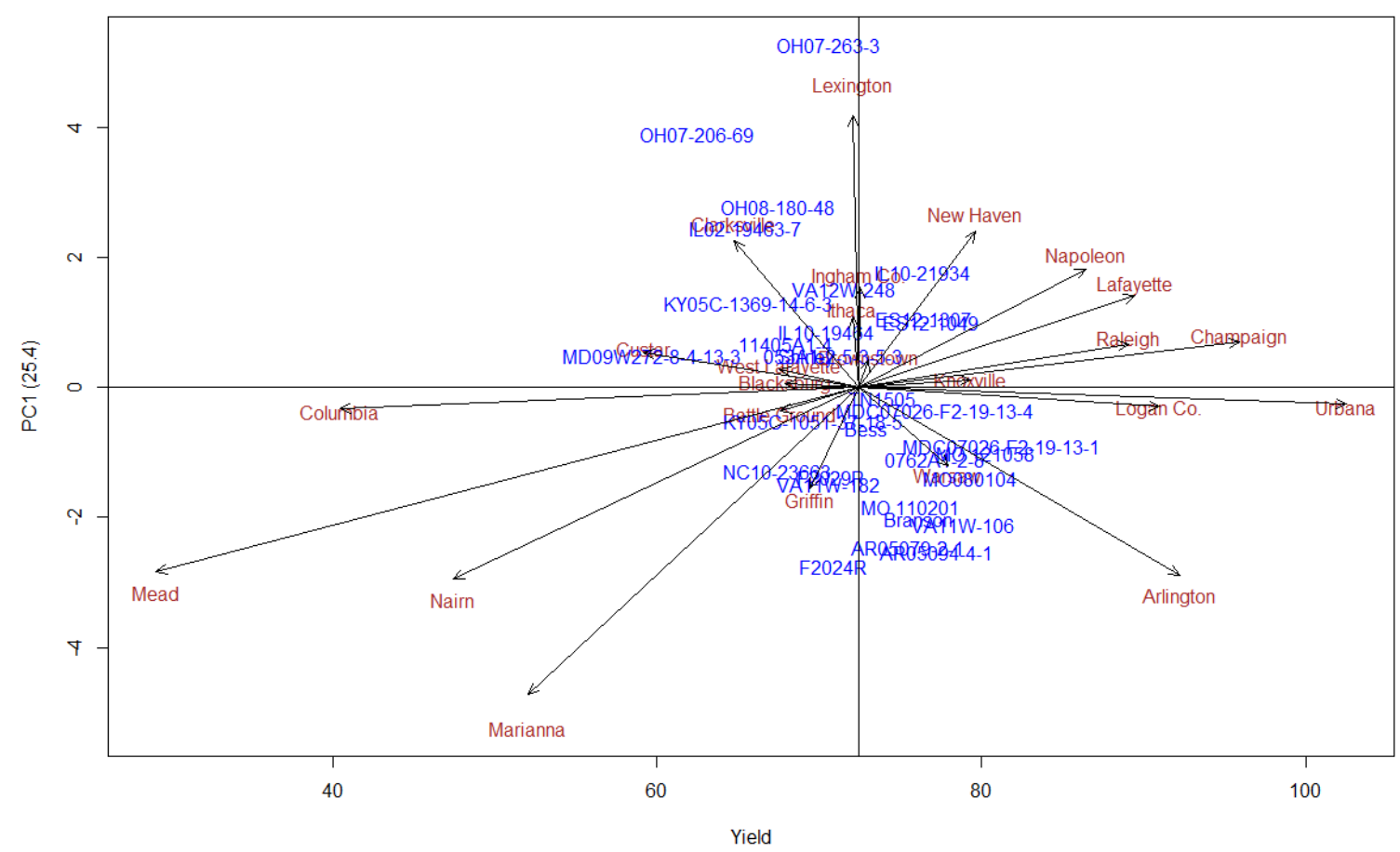

c

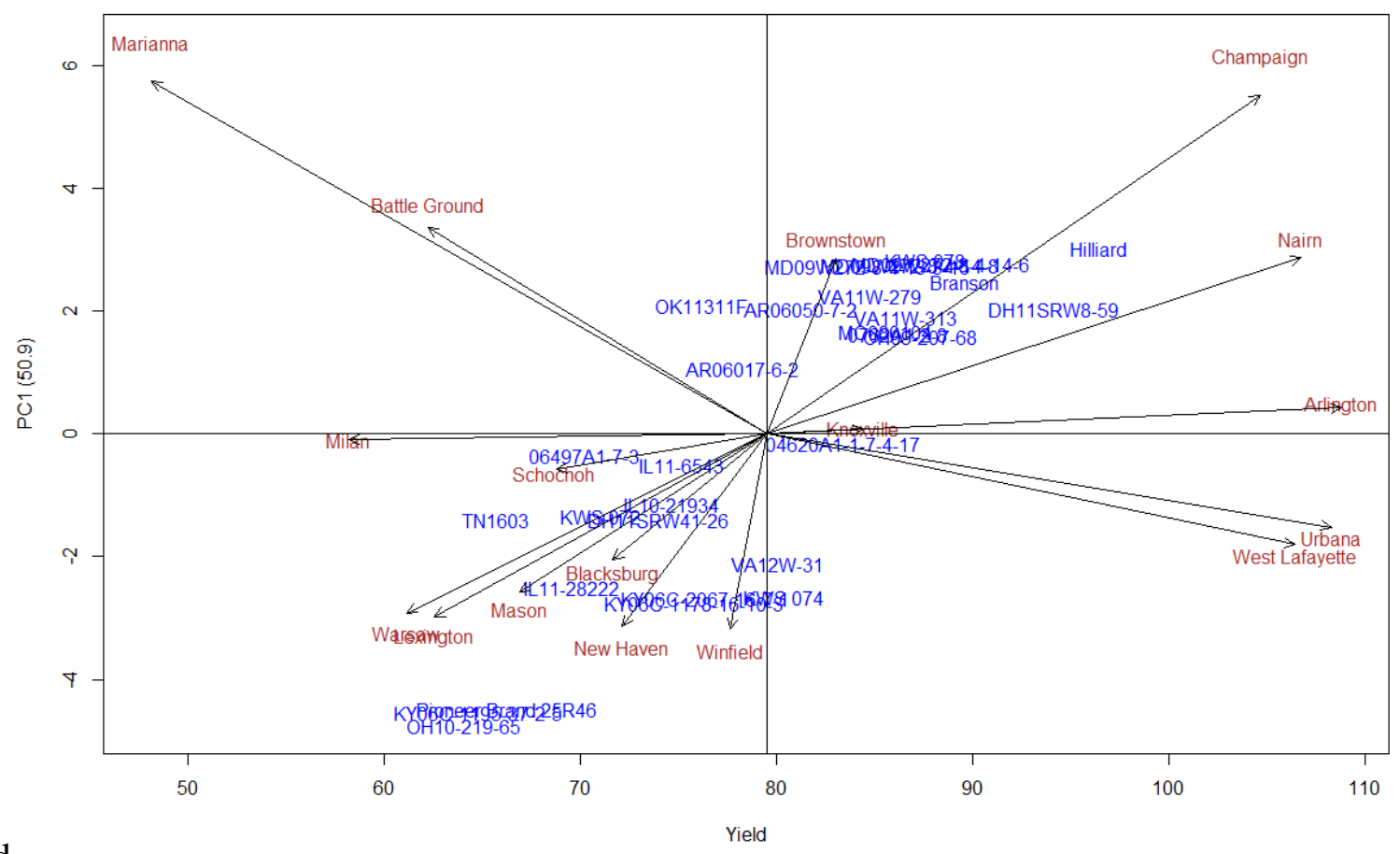

d

Figure 2. Genotype and GE interaction biplots for grain yield (bu/ac) of 39 genotypes and 21 locations for season 2012/13 (a), 2013/14 (b), 31 genotypes and 24 locations for season 2014/15 (c) and 30 genotypes and 24 locations for 2015/16 (d). Blue and red letters indicate genotypes and New Prairie Presslocations, respectively. 